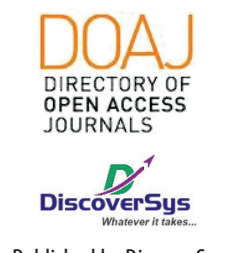

Published by DiscoverSys

\section{High ureum and creatinine level in 18-year-old male: First diagnosed with chronic kidney disease}

\author{
I Made Dwi Payana, ${ }^{1 *}$ Ni Nengah Tuti Arianthi, ${ }^{2}$ I Made Sila Darmana ${ }^{3}$
}

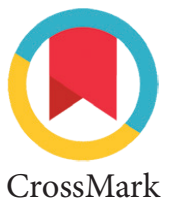

CrossMark

\section{ABSTRACT}

Introduction: Chronic Kidney Disease (CKD) needs to be rapidly diagnosed and treated correctly. The classic patient characteristics were anaemia, hypertension, oedema, albuminuria and decrease of renal function. In a few cases, CKD can occur in an atypical patient, such as in young age.

Case report: We herein report a case of an 18-year-old male with Renal failure. The patient noted to be anaemic, fatigue,

oedema, hypertension which is consisted of features typical of Chronic kidney disease. Laboratory examination revealed low haemoglobin level, high ureum and creatinin, and albuminuria. The patient underwent hemodialysis and was given Packed Red Cell (PRC) transfusions.

Conclusion: CKD had to be suspected of all age so that it can be rapidly diagnosed and treated correctly.
'General Practicioner Sanjiwani General Regional Hospital, Gianyar, Bali-Indonesia

${ }^{2}$ Faculty of Medicine, Universitas Warmadewa, Bali-Indonesia ${ }^{3}$ Clinical Pathology Department, Sanjiwani General Hospital, BaliIndonesia
*Correspondence to: I Made Dwi Payana, General Practicioner Sanjiwani General Regional Hospital, Gianyar, BaliIndonesia

dwipayana17@gmail.com

Keywords: Chronic Kidney Disease, ureum, creatinine.

Cite This Article: Payana, I.M. D., Arianthi, N.N.T., Darmana, I.M.S. 2020. High ureum and creatinine level in 18-year-old male: first diagnosed with chronic kidney disease. Intisari Sains Medis 11(1): 277-280. D0I: 10.15562/ism.v11i1.708

\section{INTRODUCTION}

Chronic kidney disease (CKD) is a common condition that refers to a long-term loss of kidney function. It tends to be diagnosed in the presence of other comorbidities (particularly hypertension, diabetes, and cardiovascular disease), isolated $\mathrm{CKD}$ is the exception rather than the rule, and CKD is associated with socioeconomic deprivation. Effective identification and management are necessary to prevent CKD progression and cardiovascular events, reduce the risks associated with acute kidney injury (AKI), and improve patient safety and medicines management. Primary care clinicians also have an essential role to play. For those working in primary care, an understanding of the condition is required to identify people with CKD, undertake appropriate risk stratification, communicate the diagnosis to patients, and work with them toward optimal management and risk reduction. ${ }^{1}$

Chronic kidney disease defined as abnormalities of kidney function or structure present for more than 3 months, with implications for health. This includes all people with markers of kidney damage and those with a glomerular filtration rate (GFR) of less than $60 \mathrm{ml} / \mathrm{min} / 1.73 \mathrm{~m}^{2}$ on at least 2 occasions separated by a period of at least 90days (with or without markers of kidney damage). ${ }^{1-6}$

CKD in primary care is commonly asymptomatic, and the exact pathology underlying its development is often unknown (as no renal biopsy is usually performed). It is identified and defined by the presence of an abnormality of kidney structure or function (or both) present for at least 3 months. It is classified by the degree of renal dysfunction, as measured by the estimated glomerular filtration rate ([eGFR] derived from serum creatinine using standard estimating equations) and by the presence or absence of structural kidney abnormality or by other evidence of chronic kidney damage, particularly albuminuria. ${ }^{1}$

The KDOQI guidelines define CKD as Kidney damage of 3 or more months duration caused by structural or functional abnormalities with or without a decreased GFR. Pathological marker, abnormalities in the blood or urine, or imaging test, may reveal kidney dysfunction. CKD may also be defined as a persistently low GFR of $<60 \mathrm{~mL} / \mathrm{min} / 1.73 \mathrm{~m}^{2}$ for 3 or more months, with our without identifiable kidney damage. ${ }^{3}$

\section{CASE PRESENTATION}

An 18-year-old Balinese male who was previously healthy presented to hospital with a 4 day of fatigue, palpitation, facial oedema. No fever nor vomiting complained. Patient did not have any prior surgeries. There was history of renal disease and dialysis on his mother but no significant history in other family members.

On Admission, Patient was noted to be afebrile, hypertensive with blood pressure of 140/90 and heart rate 92 beats per minute, normal respiratory rate with $99 \%$ O2 saturation on room air. His anthropometric measurements showed his height to be $160 \mathrm{~cm}$, his weight $65 \mathrm{~kg}$. In physical exam we 
Table 1 Complete blood count, electrolyte, kidney function test, and blood glucose

\begin{tabular}{|c|c|}
\hline Parameters & Values \\
\hline \multicolumn{2}{|l|}{ Haematology (CBC } \\
\hline WBC & $15.06 \times 10^{3} / \mu \mathrm{L}$ \\
\hline$\# \mathrm{Neu}$ & $12.49 \times 10^{3} / \mu \mathrm{L}$ \\
\hline \#Lym & $1.52 \times 10^{3} / \mu \mathrm{L}$ \\
\hline \#Mono & $0.68 \times 10^{3} / \mu \mathrm{L}$ \\
\hline \#Eos & $0.36 \times 10^{3} / \mu \mathrm{L}$ \\
\hline \#Baso & $0.01 \times 10^{3} / \mu \mathrm{L}$ \\
\hline $\mathrm{RBC}$ & $1.50 \times 10^{6} / \mu \mathrm{L}$ \\
\hline $\mathrm{Hb}$ & $4.6 \mathrm{~g} / \mathrm{dL}$ \\
\hline HCT & $13.9 \%$ \\
\hline $\mathrm{MCV}$ & $92.4 \mathrm{fL}$ \\
\hline $\mathrm{MCH}$ & $30.5 \mathrm{pg}$ \\
\hline $\mathrm{MCHC}$ & $33.0 \mathrm{~g} / \mathrm{dL}$ \\
\hline RDW-CV & $10.5 \%$ \\
\hline RDW-SD & $36.5 \mathrm{fL}$ \\
\hline Platelet & $199 \times 10^{3} / \mu \mathrm{L}$ \\
\hline MVP & $9.8 \mathrm{fL}$ \\
\hline PDW & $16.1 \mathrm{fL}$ \\
\hline \multicolumn{2}{|l|}{ Electrolyte (mmol/L) } \\
\hline $\mathrm{Na}^{+}$ & 136 \\
\hline $\mathrm{K}^{+}$ & 4.7 \\
\hline $\mathrm{Cl}^{-}$ & 102 \\
\hline \multicolumn{2}{|l|}{ Kidney Function (mg/dL) } \\
\hline Ureum & 240.6 \\
\hline Creatinin & 35.98 \\
\hline Blood Glucose (mg/dL) & 88 \\
\hline
\end{tabular}

Abbreviations: CBC, complete blood count; Hb, hemoglobin; HCT, hematocrit; MCH, mean corpuscular hemoglobin; MCHC, mean corpuscular hemoglobin concentration; MCV, mean corpuscular volume; MPV, mean platelet volume; RBC, red blood cells; RDW, red cell distribution width; WBC, white blood cells.

found facial oedema, a pale conjunctiva palpebra, and bilateral lower extremity oedema. No respiratory distress nor heart sound abnormality was founded.

Laboratory examination result showed the patient to have low haemoglobin level $(4,6 \mathrm{~g} / \mathrm{dL})$ and normocytic normochromic (MCV $92.4 \mathrm{fl}$ dan $\mathrm{MCH} 30.5 \mathrm{pg}$ ) were defined (Table 1). Renal Function test showed the patient to have azotemia with ureum of $240 \mathrm{mg} / \mathrm{dL}$ and a creatinine level of $35.98 \mathrm{mg} / \mathrm{dL}$ (Table 1). Urinalysis showed 2+ albumin and $1+$ leucocyte (Table 2). Chest x-ray was significant for cardiomegaly but no sign of pulmonary oedema (Figure 1). On abdominal x-ray showed no sign of urolithiasis or hydronephrosis (Figure 2). On Ultrasonography showed multiple

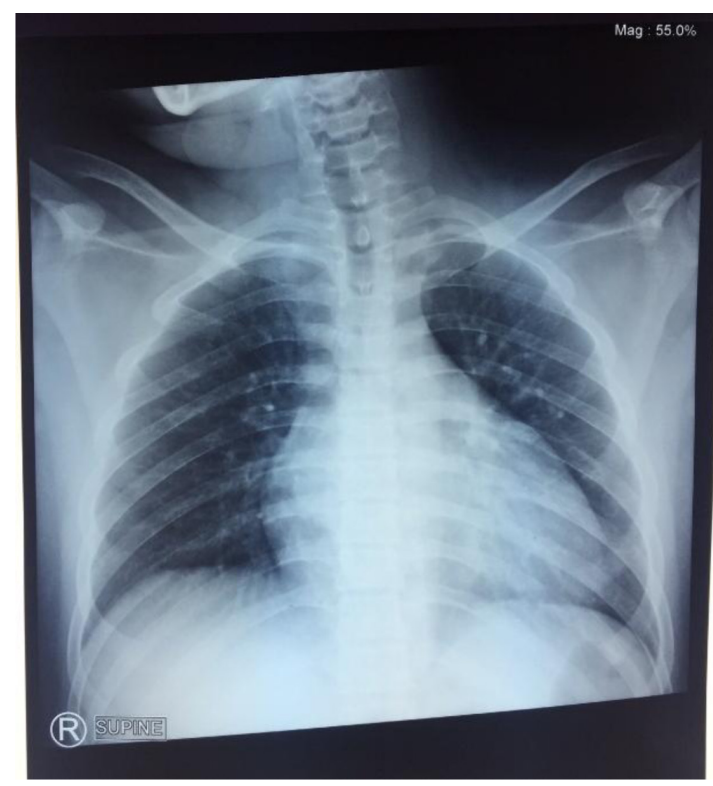

Figure 1 Chest X-ray shows no pulmonary edema

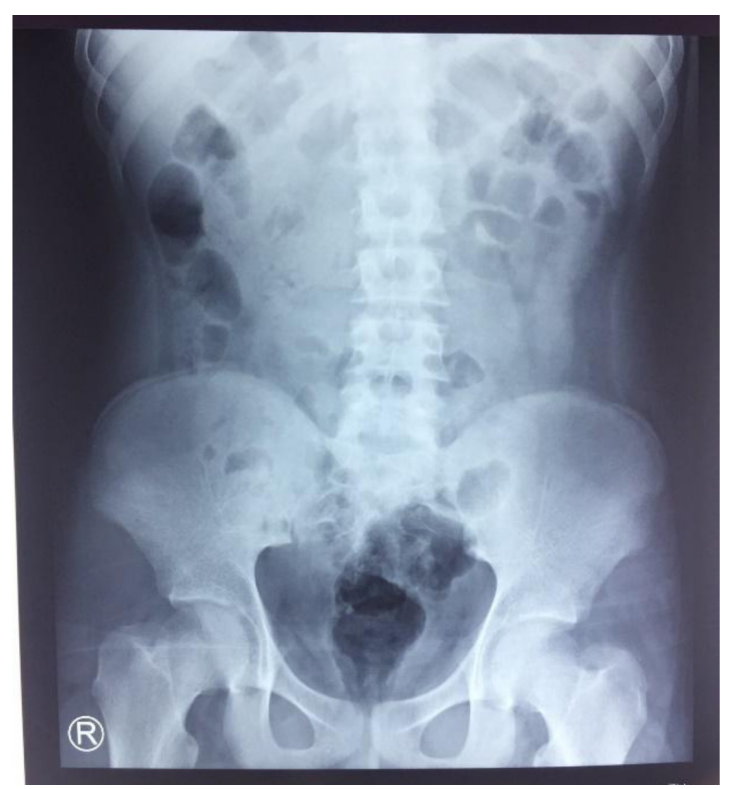

Figure 2 Abdominal X-ray shows no urolithiasis

simple cysts in right kidney with the largest size is $2.37 \times 1,07 \mathrm{~cm}$.

From these finding a diagnosis of Chronic Kidney disease stage 5 was made by the Internist. The cause of CKD or the primary renal disease in these patients is polycystic kidney disease. Patient than planned to hemodialysis and packed red cell (PRC) transfusion to correct his anemia. The patient get 1 unit of PRC transfusion per day for 5 days. Unfortunately, the patient refused to do hemodialysis. The patient still traumatized because his mother died on Kidney disease and was afraid of undergoing hemodialysis procedure. Reevaluation 
Table 2 Urinary analysis and sedimentation test

\begin{tabular}{lc}
\hline Parameters & Values \\
\hline Urine & Yellow \\
Colour & 1015 \\
Specific Gravity & 6.0 \\
pH & ++ \\
Albumin & TRACE \\
Glucose & NEGATIVE \\
Bilirubin & NORMAL \\
Urobilinogen & NEGATIVE \\
Ketones & NEGATIVE \\
Nitrite & TRACE \\
RBC & + \\
WBC & \\
Urine Sediment & $2-5$ \\
RBC & $10-15$ \\
WBC & + \\
Epithelial Cells & NEGATIVE \\
WBC Cast & NEGATIVE \\
Granular Cast & NEGATIVE \\
Oval Fat Bodies & NEGATIVE \\
Triple Phosphates & NEGATIVE \\
Calcium oxalate & NEGATIVE \\
Uric Acid & NEGATIVE \\
Fungi & NEGATIVE \\
Bacteria & \\
\hline &
\end{tabular}

of peripheral $\mathrm{CBC}$ test was performed after 5 unit PRC transfusion. The CBC test showed hemoglobin level increased to $9.8 \mathrm{~g} / \mathrm{dL}$ (Table 3). Patient was hospitalized for 7 days and discharged after his anemia was corrected and clinical condition improved.

\section{DISCUSSION}

Children, adolescents, and young adults constitute less than $5 \%$ of the end-stage kidney disease (ESKD) population and their 10-year survival ranges from 70 to $85 \%$. Despite these figures, their mortality rate is still 30 times higher than their healthy peers. They mainly die of cardiovascular causes and infection rather than from renal failure. Adolescents with CKD and ESKD experience the physical and psychological demands of puberty while having to learn to self-manage their comorbidities. ${ }^{8}$

Review of the current paediatric literature shows that, worldwide, around half of all renal failure in children is caused by some form of a congenital abnormality of the kidney and urinary tract
Table 3 Complete blood count test following PRC transfusion

\begin{tabular}{lc}
\hline Parameters & Values \\
\hline Haematology (CBC & \\
WBC & $12.01 \times 10^{3} / \mu \mathrm{L}$ \\
\#Neu & $9.91 \times 10^{3} / \mu \mathrm{L}$ \\
\#Lym & $0.97 \times 10^{3} / \mu \mathrm{L}$ \\
\#Mono & $0.84 \times 10^{3} / \mu \mathrm{L}$ \\
\#Eos & $0.28 \times 10^{3} / \mu \mathrm{L}$ \\
\#Baso & $0.01 \times 10^{3} / \mu \mathrm{L}$ \\
RBC & $3.36 \times 10^{6} / \mu \mathrm{L}$ \\
Hb & $9.8 \mathrm{~g} / \mathrm{dL}$ \\
HCT & $29.8 \%$ \\
MCV & $88.6 \mathrm{fL}$ \\
MCH & $29.0 \mathrm{pg}$ \\
MCHC & $32.8 \mathrm{~g} / \mathrm{dL}$ \\
RDW-CV & $13.6 \%$ \\
RDW-SD & $45.0 \mathrm{fL}$ \\
Platelet & $189 \times 10^{3} / \mu \mathrm{L}$ \\
MVP & $9.8 \mathrm{fL}$ \\
PDW & $16.0 \mathrm{fL}$ \\
\hline
\end{tabular}

Abbreviations: $\mathrm{CBC}$, complete blood count; $\mathrm{Hb}$, hemoglobin; $\mathrm{HCT}$, hematocrit; $\mathrm{MCH}$, mean corpuscular hemoglobin; $\mathrm{MCHC}$, mean corpuscular hemoglobin concentration; MCV, mean corpuscular volume; MPV, mean platelet volume; RBC, red blood cells; RDW, red cell distribution width; WBC, white blood cells.

(CAKUT) and a further $20 \%$ from other congenital and familial disease. ${ }^{9}$

The UK Renal Registry data for the period 2000- 2006 had been reviewed, and Primary Renal Disease (PRD) reported for all aged 18-39 years. For comparison, US Renal Data System (USRDS) results are available for age groups $0-19,20-29$ and 30-39 years. These data are also compared with data reported by the British Association of Paediatric Nephrology (BAPN). These data showed 14 diagnostic groups for primary renal diagnostic..$^{9}$ The top 10 of the diagnosis are renal dysplasia, glomerular disease, obstructive uropathy, tubule-interstitial disease, congenital nephrotic syndrome, metabolic disease, renovascular problems, CKD of uncertain aetiology, polycystic kidney disease, CKD from nephrotoxicity drugs.

People with any risk factor such as diabetes, hypertension, Acute kidney injury, Cardiovascular disease (ischemic heart disease, chronic heart failure, peripheral vascular disease, or cerebral vascular disease) Structural renal tract disease, renal calculi, or prostatic hypertrophy, multisystem diseases with potential kidney involvement, for example, systemic lupus erythematosus, Family history of end-stage kidney disease (GFR category G5) or hereditary 
kidney disease and Opportunistic detection of hematuria should be offered for testing CKD. ${ }^{1}$ This patient had hypertension and family history (mother) of end-stage kidney disease. During the early stage of CKD, patient tend to be asymptomatic or may have few signs and symptoms. As kidney function worsens patient will begin accumulate uremic toxins and develop symptoms such as fatique, nausea, anorexia, lethargia weight loss and pruritus. In CKD stage 4 and 5 patient are likely to experience anemia, as a result of reduced erythropoietin production, hyperkalemia due to impaired potassium excretion, uremia which predisposes patients to gastrointestinal bleeds and uremic cardiomyopathy, impaired vitamin D metabolism which can cause hyperparathyroidism that may affect level of both calcium (hypocalcemia) and phosphate (hyperphosphatemia), thereby impacting on bone turnover. ${ }^{10}$ From physical findings, we found facial oedema, a pale conjunctiva palpebra, and bilateral lower extremity oedema and the diagnosis was made based on clinical features and supported by laboratory findings. This patient has decreased of GFR $\left(3.96 \mathrm{~mL} / \mathrm{min} / 1.73 \mathrm{~m}^{2}\right)$ estimated with the Cockcroft-Gault Formula, albuminuria, urine sedimentation abnormalities and anaemia ( $\mathrm{Hb} 4.6 \mathrm{gr} / \mathrm{dL})$. Anemia is a common complication in CKD secondary to impaired erythropoiesis. ${ }^{10}$ As CKD progresses, so does the prevalence of anaemia in these patients. Factors such as malnutrition, blood loss, iron deficiency, inadequate dialysis, and uncontrolled secondary hyperparathyroidism should always be kept in mind while managing resistant anaemia. ${ }^{2}$

\section{CONCLUSION}

Chronic Kidney Disease can occur at any age. In Young people with risk factor especially with classic clinical features of kidney disease should undergo clinical and laboratory examination so it can be rapidly diagnosed and treated correctly. Chronic kidney disease is a growing health burden. Awareness of it among physicians is essential in early diagnosis and treatment.

\section{CONFLICT OF INTEREST}

The author declares there is no conflict of interest regarding publication of current article.

\section{ETHICS IN PUBLICATION}

Patient had received signed inform consent regarding of publication of the medical data in journal article.

\section{REFERENCES}

1. Simon DS Fraser, Tom Blakeman. Chronic kidney disease: identification and management in primary care. Pragmatic and Observational Research. 2016:7:21-3.

2. Vimal Master Sankar Raj, Jessica Garcia, Roberto Gordillo. 17-Year-Old Boy with Renal Failure and the Highest Reported Creatinine in Pediatric Literature. Hindawi Publishing Corporation Case Reports in Pediatrics. 2015; Article ID 703960:1-8.

3. Laurence EC. The Stage of Chronic Kidney Disease and the Estimated Glomerular Filtration Rate. The Journal of Lancaster General Hospital. 2006;1(2):1-7.

4. Jennifer RL, Harrison RV, Masahito J, Rajiv Saran, Annie Z. Management of Chronic Kidney Disease. Guidelines for Clinical Ambulatory; 2019.

5. Robert T, Abbas K, John RS. Chronic Kidney Disease and its complications. Prim Care Clin Office Pract. 2008;35:329-344.

6. Borisov VV, Shilov EM. Chronic renal failure. Urologiia. 2017;1(Suppl 1):11-18.

7. Eleftheria T, Vagia Boudouri, Areti Stavpropoulou, Kostyas S, Michael R, Zacharias Z. Cause and complications of chronic kidney disease in patient on dialysis. Health science journal. 2014;8(3):1-9.

8. Maria EF, Alexander Miles, Meredith LS. Adolescents and Young Adults with Chronic or End-Stage Kidney Disease. Blood Purification; 2016;41:205-210.

9. Guy HN. Primary renal disease in young adult. Nephrol Dial Transplan. 2010;25:10025-1032.

10. Reena P. Chronic Kidney Disease Clinical Features and renal replacement therapies. Clinical Pharmacist. 2011;3:13-19.

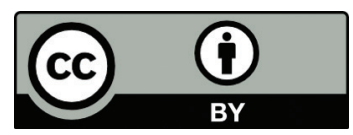

This work is licensed under a Creative Commons Attribution 